\title{
Indonesian railway accidents - utilizing Human Factors Analysis and Classification System in determining potential contributing factors
}

\author{
Hardianto Iridiastadi ${ }^{\mathrm{a},{ }^{*}}$ and Zulfa Fitri Ikatrinasari ${ }^{\mathrm{b}}$ \\ ${ }^{a}$ Faculty of Industrial Technology, Institut Teknologi Bandung, JL.Ganesha No.10, Bandung 40132, Indonesia \\ ${ }^{\mathrm{b}}$ Graduate Program, Universitas Mercu Buana, JL. Menteng Raya No. 29, Jakarta 10340, Indonesia
}

\begin{abstract}
The prevalence of Indonesian railway accidents has not been declining, with hundreds of fatalities reported in the past decade. As an effort to help the National Transportation Safety Committee (NTSC), this study was conducted that aimed at understanding factors that might have contributed to the accidents. Human Factors Analysis and Classification System (HFACS) was utilized for this purpose. A total of nine accident reports (provided by the Indonesian NTSC) involving fatalities were studied using the technique. Results of this study indicated 72 factors that were closely related to the accidents. Of these, roughly $22 \%$ were considered as operator acts while about $39 \%$ were related to preconditions for operator acts. Supervisory represented $14 \%$ of the factors, and the remaining (about $25 \%$ ) were associated with organizational factors. It was concluded that, while train drivers indeed played an important role in the accidents, interventions solely directed toward train drivers may not be adequate. A more comprehensive approach in minimizing the accidents should be conducted that addresses all the four aspects of HFACS.
\end{abstract}

Keywords: Indonesia, railway accidents, safety, HFACS, human error

\section{Introduction}

The prevalence of Indonesian railway accidents has become an area of great concern, particularly since there has been an increase in the number of fatalities in the past decade. More than 700 accidents were reported by the Ministry of Transportation between the year of 2004 - 2010, which included derailments and collisions. Crashes between trains represented roughly $5 \%$ of the accidents, while nearly $20 \%$ of the accidents involved collisions with other motor vehicles. These accidents resulted in more than 360 fatalities and injuries to more than 1200 passengers, of which more than half required hospitalization.

While the Indonesian National Transportation Safety Committee (NTSC) has investigated potential causes related to these accidents, the findings have been fairly insufficient. Human error is usually cited as the main cause, similar to what has been indicated in aviation safety [7]. With respect to the Indonesian railway, however, it is not clear what constitutes this error. In the majority of cases, train drivers are usually blamed for the accidents.

This study was conducted with an objective of determining factors that could potentially lead to an accident. The objective was achieved by utilizing Human Factors Analysis and Classification System (HFACS). Introduced by Shappel and Wiegmann [7], this method classifies causes of accidents into four groups/levels of factors (unsafe acts, preconditions for unsafe acts, unsafe supervisory, and organizational influences). This method was based on the 'Swiss Cheese' model of accident causation,

\footnotetext{
*Corresponding author. E-mail: hiridias@vt.edu.
} 
in which an accident occurs due to failures that run through holes that are aligned across several layers of defence mechanisms [4]. Initially used for the aviation industry, the HFACS method can be used for accident investigation and to systematically improve system safety. One of its strength is the focus on human operators.

The Indonesian NTSC has its own investigation method, but the results were often superficial. Human aspects were typically labeled as 'human error', without knowing clearly what constitutes the error. HFACS had never been applied in railroad accident investigations, and therefore was used as a new framework in this study.

\section{Method}

Within the past decade, nearly 1200 railroad accidents/incidents have ocurred, as indicated by the Ministry of Transportation. Of these, only about 3\% have been investigated by the Indonesian NTSC. In this study, nine reports of past accidents (provided by the Indonesian NTSC) were studied and classified using HFACS. A more recent framework developed by Reinach and Viale [9] could have been utilized, since it is directed toward railroad industry. However, no data at the time were available for this framework.

In using HFACS, all investigation reports were obtained and specific information pertaining to the chronoloy of the accidents were re-written. Next, all the factors related to the accidents were identified, and later grouped into one of the HFACS levels. The classifications were made with the help of an expert (investigator) provided by the NTSC.

\section{Results}

Each accident were characterized by $4-12$ contributing factors, and a total of 72 contributing factors were identified. A total of 16 factors $(22 \%)$ were grouped into unsafe operator acts. These included a variety of phenomena, ranging from disobeying a light signal, to changing the 'rail track transfer mechanism' without permission, to driving the locomotive with no authorization. There were also perceptual errors, that included missreading the T100 document, misunderstanding light signals, and misinterpreting signs given by other personnel. Responding incorrectly to the signals was also identified.

Twenty-eight factors (39\%) were grouped into the preconditions for unsafe acts. These ranged from boredom due to delays in the schedule to fatigue and medical illnesses that the drivers had prior to his duty. Furthermore, falling asleep/drowsiness was found during the examinations of the report. In addition, a few failed communications and coordinations were also reported immediately before an accident occured. Operators over 50 years of age had been claimed to contribute to slow response to dynamic signals; however, it was not clear to what extent this was related to the accidents.

The third level was the supervisory factors, which constituted $14 \%$ of all the factors identified. These factors included inadequate scheduling of drivers and the absence of driver's performance record. This information was valuable in determining, for example, if a driver was ready for his duty. In a few cases, problems with the communication instrument and the braking system were not resolved completely. A recurring problem that was not addressed satisfactorily was the fact that passengers were allowed to be inside the locomotive cabin. While the supervisors acknowledged this, no action was taken. This was typical, since the drivers (in return) often received some money from the passengers. It was also common that certain minor violations were not deemed important, and went unpunished. Broken train lights (that indicated end of the train cars) was another example showing a safety issue that was not addressed adequately.

With respect to the fourth level (organizational factors), several problems were identified. These include poor locomotive maintenance, allowing crew with no permit to operate the train, and incomplete information received by the drivers with regard to changes and maintenance activities of railway tracks and signals. It is interesting to note that there were several signal systems in place, developed by different vendors, and these systems were under the responsibility of another directorate. Moreover, delayed schedules were common due to various causes, but the climate was to put this responsibility to the drivers. These drivers, consequently, felt the obligation to drive the train faster than the speed limit. All the above conditions represented $25 \%$ of the factors identified to be related to the accidents.

\section{Discussion}

This study sought to understand potential root cause of railroad accidents in Indonesia by employing HFACS methodology. Findings of this study showed that frontline personnel (such as train drivers) did make errors (unsafe act). The greatest 
$(39 \%)$ portion of the factors, however, were related to conditions influencing the drivers. Fatigue, drowsiness, and boredom, were among the preconditions related to unsafe act, as cited in the literature [3].

Results of this study clearly showed that further studies and interventions should probably be directed first toward the noted preconditions. Issues such as workload, fatigue, sleepiness level, as well as their effects on performance should be carefully investigated. Falling asleep while performing duties is not uncommon among train drivers in Indonesia. While the statistics is not available, one of the recent major accident in 2010 was clearly due to the sleepiness while driving. Both the amount of sleep and sleep quality prior to performing duties certainly play an important role [8].

The work of Noy and colleagues [10,1], for example, could be used as a framework in gaining the answer to the above issues. Also important is finding a methodology that is practical yet reliable and sensitive in assessing readiness, as well as monitoring fatigue and sleepiness experienced during the job. To date, the common assessment techniques only include blood pressure and heart rate measurements. Body temperature should also be measured, but it is seldom conducted. Among interstate bus drivers, urinary samples are sometimes obtained. The authorities, however, typically only look for the use of illegal drugs. Again, techniques that are more objective and relevant to assess readiness should be sought and developed. More objective method, such as the use of Psychomotor Vigilance Test (PVT) [2] or biomarkers [5], could also be employed. Practical tools that assess cognitive functions will certainly also be beneficial.

Another finding worth discussing is the fact that a substantial portion $(25 \%)$ of the factors leading to accidents were beyond the drivers' control. Specifically, the organizational aspect had become an environment that was not conducive to the safe operations of the train. It is probably unfortunate that the drivers were usually the first to blame (and consequently sentenced to jail), while no one higher up in the organization was held accountable. The aforementioned figure clearly indicates that systematic interventions should also be directed toward procedural aspects and organizational policies and climate. This strategy will probably much more effective in minimizing chances of railway accidents, since it will cover much broader operational aspects of the organization.
Examples of interventions may include satisfactory maintenance of locomotives and train cars, evaluations of signal technology, improved cooperations and communication across departments, and better human resource management. The latter could address issues of operators' age, training, scheduling, safety behaviour, work hours, and fatigue management [6]. It is worth noted that many have complained about the lack of funding given by the Indonesian government, despite the importance of this mode of transportation. This might be true, but it is believed that there are still certain cost-effective measures that can be employed by the train operators in order to reduce the likelihood of railroad accidents.

The other two groups of factors that should also receive attention are operator acts and the supervisory factor. These issues should also be addressed carefully. It is in our opinion, however, that interventions toward the two levels discussed earlier will reduce the number of causal factors in these two groups.

In this investigation, the use of HFACS has highlighted some potential underlying causes of railway accidents. Additionally, this methodology has provided insights on what interventions should be done first. HFACS has never been employed by the Indonesian NTSC, and is probably a valuable complement to the investigation technique currently in place. This study, therefore, suggests the use of HFACS as an objective and more comprehensive approach to railway accident investigations.

It is worth noting that, while HFACS has been viewed valuable, its use may not be necessarily straightforward. Arguments among investigators often ocurred when trying to classify factors into HFACS levels. Factors related to poor supervisions, for example, could also be thought as a characteristic of organizational climate. Thus, the end results could be different from one investigator to another. This limitation certainly requires further examination.

\section{References}

[1] A. Williamson, D.A. Lombardi, S. Folkard, J. Stutts, T.K. Courtney, and J.L. Connor, The link between fatigue and safety, Accident Analysis and Prevention 43 (2011), 498-515.

[2] G.D. Roach, D. Dawson, and N. Lamond, Can a shorter psychomotor vigilance task be used as a reasonable substitute for the ten minute psychomotor vigilance task?, Chronobiology International 23 (2006), 1379-1387.

[3] J. Dorrian, G.D. Roach, A. Fletcher, and D. Dawson, Simulated train driving: Fatigue, self awareness, and cognitive disengagement, Applied Ergonomics 38 (2007), 155-166. 
[4] J. Reason, Human error: models and management, BMJ 320 (2000), 768-770.

[5] K. Vangelova, The effect of shift rotation on variations of cortisol, fatigue, and sleep in sound engineers, Industrial Health 46 (2008), 490-493.

[6] P. Gander, L. Hartley, D. Powell, P. Cabon, E. Hitchcock, A. Mills, and S. Popkin, Fatigue risk management: Organizational factors at the regulatory and industry/company level, Accident Analysis and Prevention 43 (2011), 573-590.

[7] S.A. Shappel and D.A. Wiegmann, Human Factors Analysis and Classification System, Federal Aviation Administration, U.S. Department of Transportation (2000).
[8] S.M. Jay, D. Dawson, and N. Lamond, Train drivers' sleep quantity and quality during extended relay operations, The Journal of Biological and Medical Rythm Research 23 (2006), 1241-1252.

[9] S. Reinach and A. Viale, Application of human error framework to conduct train accident/incident investigation, Journal of Accident Analysis and Prevention 38 (2006), 396 406.

[10]Y.I. Noy, W.J. Horrey, S.M. Popkin, S. Folkard, H.D. Howarth, and T.K. Courtney, Future directions in fatigue and safety research, Accident Analysis and Prevention 43 (2011), 495-497. 